\title{
Use of Peer Review of Projects to Enhance Upper Level Geotechnical Engi-
} neering Courses

Dr. James L. Hanson PE, California Polytechnic State University

Professor, Civil and Environmental Engineering Department, Cal Poly - San Luis Obispo 


\title{
Use of Peer Review of Projects to Enhance Upper Level Geotechnical Engineering Courses
}

\begin{abstract}
Student peer review has been integrated to multiple upper level (i.e., graduate and senior technical elective) geotechnical engineering courses at California Polytechnic State University. The peer review process was established as an integral part of a term project that included a written report and oral presentation to the class. A staged sequence of deadlines and milestones was administered to assure that students maintained progress with their projects. The format of the term papers was highly prescribed and based on a template for technical conference manuscripts. Content from the student projects was included in the final examination supporting a students teaching students integrated learning environment. Peer review was determined to be beneficial to the students in terms of both technical content and writing skills. Student assessment of the teaching methodology is provided. Faculty observations of experiences are described in the paper and suggestions are provided for effective use of this teaching methodology.
\end{abstract}

\section{Introduction and Background}

Peer review is common for all scientific publications as well as for engineering design work in professional practice. Integration of peer review to the curriculum has been reported for a variety of implementation modes. Limited experiences in this regard have been reported for civil engineering coursework in relation to technical writing. Rationale for including peer review in coursework includes emphasizing the development of technical writing skills and promoting an active and collaborative classroom environment. Inclusion of professional skills in the civil engineering curriculum has become increasingly important through the implementation of the Body of Knowledge. ${ }^{1}$

In some cases of implementing peer review into the classroom experience, peer review is considered part of writing in teams. ${ }^{2,3,4}$ Conventional team writing has been documented to have limited interactions in producing cohesive final written documents. ${ }^{4,5}$ In at least one instance (Ref. 4), a highly structured writing cycle was implemented to allow laboratory team members an opportunity to serve in different roles associated with typical peer review process (i.e., lead author, reviewer, editor). These roles were rotated to permit each student an opportunity to serve in each role during the term. In addition, prescriptive content both for writing assignments ${ }^{4}$ and for peer review/grading rubrics (e.g., Calibrated Peer Review, CPR) ${ }^{6}$ have been developed. The CPR allows web-managed peer review administration for courses. Gragson and Hagen (Ref. 4) reported reducing the number of assignments (by combining topics) after incorporating peer review as to emphasize fewer, more substantial writing assignments compared to the conventional curriculum. 
Benefits to students through exposure to peer review in the classroom have been reported to include: deepened understanding of subject matter, improved writing skills for Masters theses, improved assessment of their own work, and for the case of appropriate student matches for author and reviewer, knowledge leaps for both students. ${ }^{7}$

Based on the demonstrated benefits of incorporating peer review in coursework, especially using a structured writing cycle, an investigation was conducted to evaluate the use of peer review of technical writing assignments in upper level geotechnical engineering courses at California Polytechnic State University. The impacted courses were 500-level geotechnical and geoenvironmental engineering graduate courses that also serve as technical electives for seniorlevel students. The term paper assignment represented a significant portion of the course (constituting $25 \%$ of the course grade) and the peer review components represented a central aspect of the project that largely controlled the timeline for submittal of project deliverables. Students reviewed multiple term papers anonymously. The assignment was highly structured to best take advantage of the peer review framework. The novelty of this methodology relates to providing opportunities for students to respond to the reviews and modify manuscript and technical content for presentation in light of the reviews.

\section{Teaching Methodology}

A term project and presentation on an individual topic related to a geotechnical case history or specific geotechnical/geoenvironmental engineering application was required in the affected courses. Selection of topics was made by the students relatively early in the term (e.g., during week 5 of a 10-11 week quarter). Selection of topics was handled on a first notification to instructor basis and no duplicate topics were allowed within the class. Depending on class size and balance of undergraduate to graduate students, papers were either completed individually or in pairs. One method of administrative handling of grouping was to require students registered as graduate students to complete the entire assignment individually and for undergraduates to complete the entire assignment as a pair of students where pairings were self-selected. Flexibility was allowed if students wanted to work individually on a project.

For perspective, the reports were expected to provide a general background and historical perspective of the subject matter, an analysis of applicable design methods used, and some numerical design considerations (e.g., examples of design calculations, specifications, or field testing analysis). The primary focus of the reports was related to the design and performance details of a case history or parametric evaluation related to the specific topic selected. The reports were on the order of 2000-2500 words of text (in addition to figures). The assignment required that the references for the paper included at least two archival journal articles, two textbooks, and one communication with a practitioner (i.e., personal communication).

It was expected that numerical content representing 500-level coursework be included in the projects. A base expectation was that some numerical content (and associated new conclusions) that had not been previously published be included in the report. The assignment is therefore aligned with high levels of cognitive achievement (e.g., Bloom's Taxonomy) and goes well beyond a literature review. It was expected that some type of parametric evaluation be conducted 
that was related to the topic selected. As an example, students identified a case history related to use of geotextiles for reinforcement applications. Their report provided background context, design/analysis calculations, comments as appropriate to the relative success of the project, and finally, a brief analysis that involves one of the variables at hand (e.g., vertical spacing, tensile strength of geotextiles, backfill soil properties). In this way, the projects contained a connection to practical problems and provided an opportunity for investigating, in a systematic manner, the analysis and design concepts associated with the selected topic.

A highly specified format was required for production of the reports. Formatting instructions and a word processing template were provided to support a common appearance for all the papers in the class. The two-column, small font (9 point) format was used to provide a consistent, formal appearance. The format template was largely based on typical international conference proceedings format. The specific format was required to introduce students to the typical requirements of publishing.

In addition to the written report, an oral presentation to the class was required as part of the project. Duration of the oral presentations was approximately 8-10-minutes, depending on specific class size and number of sessions devoted to student presentations (typically 2 class sessions). Additional time was allowed in the schedule after each presentation for questions and discussion. The entire project was worth approximately $25 \%$ of the course grade. The written report accounted for two-thirds of the grade and the presentation for the remaining one-third. The general timeline and grading details are provided in Table 1.

Table 1. Phased Deadlines for the Project

\begin{tabular}{|l|c|c|}
\hline Aspect of Project & $\begin{array}{c}\text { Timing } \\
\text { (Due Date) }\end{array}$ & Grade \\
\hline Project formally introduced & Week 3 & NA \\
\hline Topic selection & Week 5 & $2 \%$ \\
\hline Refined scope including key references and substantive outline & Week 6 & $5 \%$ \\
\hline Draft report distributed for peer review & Week 9 & $30 \%$ \\
\hline Sharing of peer review comments & Week 9 & $10 \%$ \\
\hline Submission of final written reports & Week 10 & $20 \%$ \\
\hline Oral presentations & Week 10 & $33 \%$ \\
\hline
\end{tabular}

The extended timeline associated with the staged deadlines was in place to assure systematic and substantive progress on the projects throughout the duration of the academic term. Preliminary aspects of project progress were graded relatively lightly, however, having some weighting on grade associated with these aspects (i.e., timely selection of topic, preliminary list of key references, and paper outline) encouraged students to keep pace with the expected schedule. 
The peer review process was conducted over a single week period of the term. The reviews were conducted anonymously (i.e., single-blind system where reviewers' names were not revealed to the authors). Draft papers were submitted for review. The relative weighting for grading was relatively high for the draft paper to assure that an strong effort was made to produce a nearly final version of the term paper. Three copies of draft reports were submitted to the course instructor. Two copies of draft papers were distributed amongst the students in the classroom for peer review, whereas the third copy was reviewed by the instructor. Generally, random assignment of reviewers was used for the peer review process. On certain occasions, specific reviewers were selected for given projects (e.g., making sure that each graduate student project had at least one graduate student review, allowing authors with similar topics to review each other's reports). The review process itself accounted for $10 \%$ of the project grade. For this aspect of the assignment, students were evaluated on the degree of constructive criticism that was applied during their reviews.

Students were provided guidelines and a general example of how to prepare review of a manuscript. Some aspects of journal review guidelines for ASCE journals were incorporated into the expectations. The levels of the reviews (i.e., expectations for quality of the papers) were adjusted from the ASCE guidelines to be better aligned with the project scope, timeline, and knowledge base of the student authors. The student reviews were conducted entirely qualitatively. In their reviews, students were expected to: a) briefly summarize the subject matter of the manuscript; b) comment on overall writing style and organization of the manuscript; c) identify specific problems with spelling, grammar, and/or sentence structure; d) comment on relevance and thoroughness of literature review provided in the manuscript; e) evaluate the methodology used for numerical content in the manuscript; and f) provide recommendations for improvement to the manuscript. The instructor provided similar feedback and provided a grade (that was independent of the student reviews). Students were encouraged to mark manuscripts directly with comments and provide a separate summary of their review.

Copies of the reviews were provided to the authors anonymously. The review from the instructor was apparent as it was more thorough, generally more critical, and contained both familiar penmanship and a numerical score for the draft paper. The authors had approximately 1 week to modify their papers to incorporate changes recommended during the review process. Students were required to provide a brief response to reviewers (a point-by-point response was not required, simply a statement related to reflection on reviewer recommendations versus modifications made to the paper). Final papers were due 1 day prior to the oral presentations. A compilation of all papers (i.e., "proceedings" for the course) was prepared and distributed to all students in the classroom before the oral presentations. The technical content in the reports and presentations was included in the final examination. The examination was open book format, so the students had access to the term paper compilations for study and during the examination. Some questions were informational, whereas others were calculation-based. On at least one occasion, a single question from every presentation was present on the final exam. 


\section{Experiences and Assessment}

A combination of faculty observations and formal assessment from a survey administered to students is provided. First, general observations are provided. Following, a summary of survey results is provided. Then, benefits, challenges, and recommendations for adopting this teaching methodology are provided.

Overall, students were highly engaged in the peer review process. Having a portion of the grade associated with the peer review was determined to be helpful in encouraging thoughtful and thorough reviews of manuscripts. Including technical content derived from the term projects on the final examination promoted an integrated learning environment (i.e., students teaching students). Knowledge ahead of time that content would be on the final examination led to a seriousness in listening to the oral presentations beyond what the instructor has seen for conventional term paper oral presentations. The peer review exercise coupled with the highly involved term project provided added technical depth to the course. A higher level of interaction among students in the classroom was observed as compared to a conventional classroom. The high level of interaction was particularly evident during Q\&A session of the oral presentations where familiarity with manuscript content was apparent.

In addition, the peer review promoted improved student writing skills (and personal reflection of these skills) that benefitted students for activities following the class including entering industry workforce or pursuing graduate education, specifically in terms of writing a thesis. Students reported that the peer review exercise was difficult, but valuable. The compilation of papers serves as a nice souvenir for the class. When at a high technical proficiency, formatted so nicely, and bound together with all the other papers, the manuscripts served as a matter of pride for the students in the class.

Students participating in these courses that eventually pursued graduate school were well prepared for aspects related to publication of technical writing including conference and journal publications as well as their theses. On numerous occasions, the term project template was referenced in conversation with graduate students in terms of providing context for quality and consistency in preparation of a document.

Formal assessment was conducted for one experience utilizing this teaching methodology for CE587 Geoenvironmental Engineering. Questions related to the process of conducting a peer review (i.e., acting as reviewer), the process of receiving review comments, and the experience with staged deadlines was assessed using an online anonymous survey that was administered outside of class time. Twelve students were enrolled in the course (10 of which were graduate students). Nine survey responses were submitted. A summary of the survey responses is provided in Table 2. Additional student comments are also provided. 
Table 2. Summary of Student Assessment

\begin{tabular}{|l|c|c|c|c|c|}
\hline Survey Question & $\begin{array}{c}\text { Strongly } \\
\text { Agree }\end{array}$ & Agree & Neutral & Disagree & $\begin{array}{c}\text { Strongly } \\
\text { Disagree }\end{array}$ \\
\hline $\begin{array}{l}\text { 1. The process of conducting peer reviews } \\
\text { of other students' papers was beneficial for } \\
\text { learning about new topics in detail. }\end{array}$ & $\begin{array}{c}1 \\
(11 \%)\end{array}$ & $\begin{array}{c}7 \\
(78 \%)\end{array}$ & $\begin{array}{c}1 \\
(11 \%)\end{array}$ & 0 & 0 \\
\hline $\begin{array}{l}\text { 2. The process of conducting peer reviews } \\
\text { was beneficial for developing critical } \\
\text { assessment skills. }\end{array}$ & $\begin{array}{c}1 \\
(11 \%)\end{array}$ & $\begin{array}{c}5 \\
(56 \%)\end{array}$ & $\begin{array}{c}3 \\
(33 \%)\end{array}$ & 0 & 0 \\
\hline $\begin{array}{l}\text { 3. Receiving feedback from students was } \\
\text { helpful in developing and finalizing the } \\
\text { term project/paper. }\end{array}$ & $\begin{array}{c}2 \\
(22 \%)\end{array}$ & $\begin{array}{c}4 \\
(44 \%)\end{array}$ & $\begin{array}{c}3 \\
(33 \%)\end{array}$ & 0 & 0 \\
\hline $\begin{array}{l}\text { 4. Receiving feedback from the instructor } \\
\text { was helpful in developing and finalizing } \\
\text { the term project/paper. }\end{array}$ & $\begin{array}{c}9 \\
(100 \%)\end{array}$ & 0 & 0 & 0 & 0 \\
\hline $\begin{array}{l}\text { 5. Staged deadlines worked well for } \\
\text { keeping good pace with the workload } \\
\text { associated with the project. }\end{array}$ & $\begin{array}{c}4 \\
(44 \%)\end{array}$ & $\begin{array}{c}4 \\
(44 \%)\end{array}$ & 0 & $\begin{array}{c}1 \\
(11 \%)\end{array}$ & 0 \\
\hline
\end{tabular}

Overall, the students responded positively to the format of the assignment. The process of conducting peer reviews was documented as being beneficial, but not strongly in terms of both learning about new topics in detail and developing critical assessment skills. The students felt strongly about the benefit of receiving feedback on their draft papers, especially from the instructor ( $100 \%$ strongly agreed that this was beneficial). The students had generally favorable feedback related to the staged deadlines. Additional comments were obtained as part of the survey are presented below:

Maybe get started on the project earlier in the quarter.

For this peer reviewed assignment I would suggest possibly 2 more staged deadlines. Students could submit their introduction and background portion of their paper to sort of represent the end of the their literature review. I ended up dragging on with my literature review, which took away from my actual numerical analysis. Then students could submit a draft of their numerical analysis portion. And finally, as we did, turn in a rough draft for peer review. I know this would create a lot more work for you having to review two more submissions (intro/background and numerical analysis before a full rough draft), but it is just a suggestion.

I think the rough draft should be due two weeks before the final draft. That way, if there was recommendations to expand sections or add details we could do that bit of additional research and formulation. I liked that the paper was due before the presentation. I think maybe the Friday before presentation week so you have the whole weekend to practice the presentation without juggling the essay. At first I 
really did not want to call a practitioner because it really seemed like a hassle, but it is good since it is a quick easy phone call to help us get over that feel and make us contact professionals to build that comfort level. I also think the "two textbook" requirement should be enforced a bit loosely, because since these are contemporary and complex topics, there isn't any great coverage in textbooks and those cited were probably a bit of a stretch. Otherwise, it was a good technical writing learning experience.

It may be beneficial to ask the reviewer about what the paper was lacking contentwise or gaps in content. What additional discussion would strengthen the content of the paper.

I think the process was nice. But I'm still not quite sure about how the first draft was weighted so highly. Interesting approach.

The student comments suggest that this assignment become an even larger part of the course. The author (i.e., instructor) has been reserved about the commitment of this experience in terms of fraction of class time during the academic term. These responses suggest that students are benefiting from this central project and that expanding to become an even larger portion of the course may be warranted.

Faculty perspective related to benefits, challenges, and recommendations for this teaching methodology are provided below. Benefits of incorporating peer review of technical writing were numerous:

1) The staged deadlines for different aspects of the project over the duration of the term required students to develop research term paper systematically.

2) Providing constructive criticism is a skill that is not commonly implemented in the civil engineering curriculum, yet is required in professional practice.

3) Providing feedback over different (i.e., intermediate) phases of the project provided for improved learning of technical writing skills and results in improved term paper quality. This compares to a conventional technical writing assignment where students may simply look at a score on a term paper and neglect to look carefully at (or learn from) the marked copy with corrections associated with technical writing. Students particularly appreciated feedback from the course instructor.

4) Requiring students to respond to reviewers' comments and improve papers accordingly reinforced strong technical writing skills and allowed the grading process to serve as a means of promoting improvement and not just providing a letter grade.

5) A broader perspective for constructive criticism was available with at least 3 reviews per paper (as compared to conventional grading from one perspective). Different reviewers emphasized different aspects of technical writing in their reviews.

Challenges of this methodology included: 
1) The accelerated timeline of the assignment (i.e., starting the project early in the academic term) required that students began work on advanced technical aspects related to the course that in some cases, occurred before lecture content is covered.

2) The overall effort of grading and administering this version of assignment was significantly more than that for a conventional term paper assignment. Effort to manage logistics of firstnotification topic selection and of conducting anonymous peer reviews was significant.

3) The additional time required for conducting peer reviews of the term papers affected schedule of the course by impacting term paper deadlines and overlapping with other homework assignments late in the term. Workload for other aspects of the course may need to be modified to accommodate inclusion of peer review component.

4) Potential exists for technical errors to be present in papers and/or presentations.

5) Grading of the peer review component was somewhat difficult in terms of fairness as the quality of manuscripts provided at the draft stage was highly variable. Some draft manuscripts were missing entire sections or poorly written whereas others were of very high quality.

Recommendations for incorporating peer review of technical term papers include:

1) Provide sufficient time for phased deadlines (on the order of 5 weeks) for project deliverables.

2) Assign weighting for grading of various phases of project to assure steady progress throughout the term on the projects.

3) Provide template for manuscripts that requires students to produce a document of a highly specific configuration.

4) Distribute the final papers to promote cross-pollination of ideas and allow content to be included as part of course content (e.g., final examination). In addition, provide opportunity for students to present their work as an oral presentation. These together promote students teaching students. Watch for errors in presentations and/or papers and delicately highlight such errors to the class.

5) Plan on increased grading time earlier in the term (paper drafts) as compared to conventional end of term projects, increased administrative tasks related to peer review process, and reduced grading time at the end of the term due to the high quality of final papers.

\section{Summary and Conclusions}

A significant term project was implemented as a central part of three 500-level geotechnical/geoenvironmental engineering courses at California Polytechnic State University. Peer review of the term papers was conducted within the classroom. The following conclusions were drawn: 
- Incorporation of peer review was beneficial in promoting strong technical communication skills, self-reflection of student writing skills, and increased intellectual interactions among students in a classroom environment.

- The benefits of this teaching methodology impact students pursuing either employment in industry or graduate school. The peer review activities positively influence both technical aspects related to the course as well as technical writing skills.

- Phased deadlines over a relatively long period serve well to promote student success. Inclusion of student-produced technical content on the final examination leads to an integrated learning environment.

- Administration and grading of the assignments can be complicated.

- Students responded favorably to the format of this significant assignment. The students particularly appreciated having feedback on their draft papers from the instructor.

\section{References}

1. American Society of Civil Engineers, (2008). Civil Engineering Body of Knowledge for the 21st Century, Preparing the Civil Engineer for the Future, Second Edition, ASCE Press, Reston, VA.

2. Nelson, S. (2003). "Engineering and Technology Student Perceptions of Collaborative Writing Practices," IEEE Transactions on Professional Communications, Vol. 46, No. 4, 265-276.

3. FitzPatrick, K. A. (2004). “An Investigative Laboratory Course in Human Physiology Using Computer Technology and Collaborative Writing," Adv Physiol Educ, 28: 112-119.

4. Gragson, D. E. and Hagen, J. P. (2010). "Developing Technical Writing Skills in the Physical Chemistry Laboratory: A Progressive Approach Employing Peer Review,” Journal of Chemical Education, Vol. 87, No. 1, 6265 .

5. Hanson, J. L., and Kuraoka, S. (2008). "International Collaboration for Geotechnical Engineering Laboratory Exercises," Proceedings 2008 ASEE Annual Conference, p. 1-11.

6. Calibrated Peer Review, http://cpr.molsci.ucla.edu/Home.aspx, last accessed Jan. 3, 2013.

7. Lundquist, C. Skoglund, M. A., Granstrom, K. and Glad, T. (2013). "Insights from Implementing a System for Peer Review," IEEE Transactions on Education, Vol. 56, No. 3, 261-267. 